\title{
ABO blood grouping and COVID-19: a hospital-based study in Eastern India
}

\author{
Birasen Behera, Bidyutprava Rout, RajashreePanigrahy, Subrat Kumar Kar, Debasish Sahoo, \\ Kundan Kumar Sahu and Sarita Otta*
}

\begin{abstract}
Background: Blood group has been stated to be one of the risk factors associated with viral diseases like dengue, hepatitis virus, Norwalk virus and even the coronavirus associated with 2003 severe acute respiratory syndrome (SARS) outbreak. In addition, anti-A antibodies in experimental models have been shown to inhibit the interaction between coronavirus and angiotensin converting enzyme (ACE) receptor of the host target cell, the major receptor involved in viral pathogenesis. Thus, several workers propose an association between $\mathrm{ABO}$ blood type and coronavirus disease2019 (COVID-19) disease in many previous studies. The present study was undertaken in the Eastern part of India in line with these authors to study the association of ABO blood group of patients with COVID susceptibility and severity.

Methods: This is a retrospective study over a period of 6 months from June 2020 to November 2020 where patients who underwent quantitative real-time polymerase chain reaction (qRT-PCR) test for SARS-COV2 and having a recorded patient blood group type were considered. The qRT-PCR positive admitted cases were considered as cases, and qRT-PCR negative cases were considered as controls. Data were entered in Microsoft Excel format and analyzed by statistical method to obtain association.
\end{abstract}

Results: Consecutively obtained 5000 qRT-PCR positive patients (cases) and 11,700 (controls) were included in the present study. The mean age of cases was higher (54.24 vs. 34. 67) than the controls. Among the cases, the highest number (2379; $47.6 \%)$ of samples belonged to A blood group followed by B $(1278 ; 25.6 \%)$ while among the control group O blood group had the highest prevalence $(4215 ; 36 \%)$. Blood group A had a higher odd of testing positive (Odds ratio-2.552; $\mathrm{Cl} 2.381-2.734 ; p<0.0001$ ) than all other blood groups. A blood group is also associated with higher risk of ICU admission (Odds ratio- 1.699; 95\% Cl 1.515-1.905) and 65.3\% of this group is also associated with high viral load which gives an indication of higher disease severity.

Conclusion: Blood group A is associated with an increased susceptibility to COVID 19 infection than other blood groups. Cases of this blood group are also associated with more critical care needs and a higher viral load on testing.

Keywords: COVID-19, ABO blood type, SARS-COV2, Real-time PCR

\section{Background}

Since the declaration of COVID 19 (Coronavirus Disease -2019) as a pandemic by World Health Organization, it has created havoc worldwide with huge surge in case load and thus mortality and morbidity. There is yet no

*Correspondence: saritaotta@gmail.com

Department of Microbiology, IMS and SUM Hospital, Kalinga Nagar, Bhubaneswar 751003, India biomarker developed to detect the susceptibility of the patients to the COVID 19 disease [1]. Risk factors proposed till date are old age, male sex and chronic diseases like diabetes, hypertension and cardiovascular diseases [2]. The ABO blood group antigens are glycoproteins present mostly on surface of erythrocytes and are encoded by co-dominant alleles (A and B) present in Chromosome 9 [3]. Blood group expression varies greatly among different races and it has been associated as a genetic risk 
factor for different infectious diseases and malignancies like Hepatitis B virus, Norwalk virus, Dengue virus and even the last corona viral SARS (severe acute respiratory illness) outbreak in 2003 [4]. Anti-A antibodies inhibit the interaction between severe acute respiratory syndrome coronavirus 2 (SARS-COV 2) and Angiotensin Converting Enzyme (ACE) receptor expressed on host target cells. ACE receptors being the major target of this virus it is logical to expect an association between the ABO blood group and COVID 19 disease. Li et al. [5] was the foremost researcher to show that blood group A has a significantly higher risk of SARS-CoV2 infection and blood group $\mathrm{O}$ has a lower risk. Several other works since then have associated COVID-19 and ABO blood group [3, 6-9]. In continuation of these works, the present study aims to probe into association between $\mathrm{ABO}$ blood group and SARS-CoV-2 infection in Eastern part of India.

\section{Methods}

\section{Study setting}

The present study was conducted at IMS and SUM Hospital a tertiary care hospital with dedicated quantitative real-time polymerase chain reaction (qRT-PCR) laboratory for testing as well as wards and ICU for COVID 19 patient care. This is a retrospective study conducted over a period of 6 months from June 2020 to November 2020 where data obtained from the Hospital Information System were collected.

\section{Method}

Nasopharyngeal and oropharyngeal swabs collected from patients in viral transport medium were used for detection of SARS COV2 by qRT-PCR technique. RNA was extracted using In vitrogen kit, and qRT-PCR was performed using Taq Path kit (Thermo Fisher Scientific) on ABI 7500-Fast, Thermo-fisher machine. The cycle threshold $(\mathrm{Ct})$ value for each sample was recorded. We have collected the relevant patient admission details, laboratory parameters including blood grouping and patient disease severity from the hospital information system.

\section{Study population}

The patients, who were admitted to the hospital after testing as SARS-COV2 positive by qRT-PCR for symptoms requiring the said testing, were denoted as cases. (Inclusion criteria) Any other patient who presented to the hospital with symptoms which mandated COVID-19 testing as decided by the clinician but were negative by the qRT-PCR were denoted as controls for the present study. The patients of all age, gender and blood type were included in this study.

\section{Exclusion criteria}

The patients for whom we could not find relevant information in hospital system, those who were not admitted in this hospital among qRT-PCR positive group or those treated in outpatient basis after obtaining a positive result following testing were excluded from the study.

\section{Statistical analysis}

Data were entered in excel sheet and analysis done using standard statistical methods. Statistical analysis was performed using Graph Pad Prism 7. Data were analyzed with the $\chi^{2}$ test and Fisher's exact test to note the distribution of blood groups. Odds Ratio with 95\% Confidence Interval for all the blood types in cases were assessed with logistic regression models. Probability value $(p)<0.05$ was considered statistically significant.

\section{Ethical consideration}

All the samples collected for testing were received by the laboratory after a receiving an implied consent from the patient for diagnosis or treatment purpose in this hospital. During the tenure of the study, no individual history was disclosed in any form. This study was approved by institutional ethical committee via Ref.no/DRI/IMS.SH/ SOA/2021/174 dated 31st August 2021.The IEC is registered by registration number- ECR/627/Inst/OR/2014/ RR-20.

\section{Results \\ Distribution of cases and controls in the study as per age and sex}

A total of 16,700 patients were consecutively enrolled in the present study, among whom 5000 patients were found as SARS-COV2 qRT-PCR positive (cases) and 11,700 patients had SARS-COV2 qRT-PCR negative result (controls). Of the 5000 cases, highest number of samples belonged to 51-60 age group. The mean age of cases was much higher (54.24 vs. 34 . 67) than the controls, the difference manifesting across both the sexes (Males-55.07 vs. 32.28 ; Females -51.85 vs. 36.44 ) as well as across all the blood groups (Fig. 1). The mean and standard deviation of patients admitted in ICU and wards in this study were $55.83 \pm 15.03$ and $51.65 \pm 16.11$, respectively. Ratio of males to female was 2.9:1 in this study.

\section{Analysis of susceptibility to COVID-19 infection}

Among the cases, the highest number of samples belonged to blood group A $(2379 ; 47.6 \%)$ followed by B (1278; 25.6\%) and O (1174; 23.5\%). On the other hand, among the control group, O blood group had the highest prevalence $(4215 ; 36 \%)$ followed by $B$ blood group (3926; 33.5\%), A (3070; 26.2\%), AB (489; 4.12\%). The difference in susceptibility of cases and controls to COVID 
COVID 19 cases and controls distributed as per mean age

Cases

Control

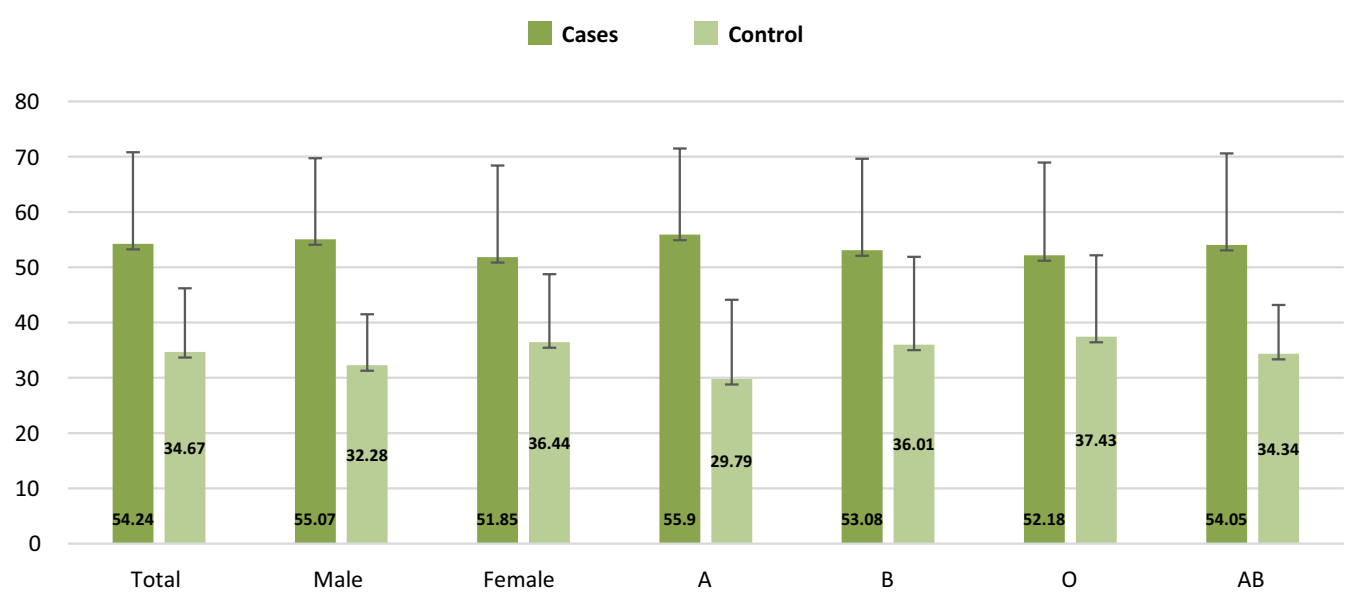

Fig. 1 COVID 19 cases and controls distributed as per mean age

Table 1 Distribution of cases and controls as per their blood types

\begin{tabular}{lllrl}
\hline Blood Group & $\begin{array}{l}\text { Number of cases } \\
\text { (\% total) }\end{array}$ & $\begin{array}{l}\text { Number of } \\
\text { controls } \\
\text { (\% total) }\end{array}$ & $\boldsymbol{x}^{\mathbf{2}}$ & $\boldsymbol{p}$ value \\
\hline $\mathrm{A}$ & $2379(47.6)$ & $3070(26.2)$ & 26.94 & $<0.0001$ \\
$\mathrm{~B}$ & $1278(25.6)$ & $3926(33.5)$ & 10.22 & $<0.0001$ \\
O & $1174(23.5)$ & $4215(36.0)$ & 15.88 & $<0.0001$ \\
AB & $169(3.4)$ & $489(4.12)$ & 2.43 & $<0.0150$ \\
Total & 5000 & 11,700 & & \\
\hline
\end{tabular}

19 among $\mathrm{A}, \mathrm{B}, \mathrm{O}$ blood group was significant at $p<0.05$ while there is no significant difference in susceptibility in AB blood group (Table 1).

Blood group A had a higher odd of testing positive than all other blood groups. It is associated with increased risk of infection (Odds ratio-2.552; CI 2.381-2.734; $p<0.0001)$ while all other blood group showed a decrease in risk (Table 2).

\section{Analysis of severity of COVID-19 infection}

Among the patients included in the study period, 2806 (56.12\%) patients were admitted in ICU while 2194 (43.9\%) patients were in wards. The cases of A, B and O were more commonly admitted to ICU than wards with significant $p$ value of $<0.00001$. On the other hand, AB blood group had no significant difference in admission of cases to ICU or wards. Blood group A is associated with higher risk of ICU admission (Odds ratio- 1.699; 95\% CI 1.515-1.905) while all other blood groups have a lower risk (Table 3).
Table 2 Comparison of ABO blood group distributions

\begin{tabular}{lcrl}
\hline Blood group & $\begin{array}{l}\text { Odds ratio (95\% } \\
\text { confidence interval) }\end{array}$ & \multicolumn{1}{c}{$\boldsymbol{x}^{\mathbf{2}}$} & $\boldsymbol{p}$ value \\
\hline A-B & $1.999(1.838-2.173)$ & 16.28 & $<0.0001$ \\
A-O & $2.781(2.557-3.025)$ & 24.26 & $<0.0001$ \\
A-AB & $2.238(1.864-2.687)$ & 8.83 & $<0.0001$ \\
A-Non-A & $2.552(2.381-2.734)$ & 26.94 & $<0.0001$ \\
B-Non-B & $0.680(0.635-1.584)$ & 10.22 & $<0.0001$ \\
O-Non-O & $0.545(0.505-0.588)$ & 15.88 & $<0.0001$ \\
AB-Non-AB & $0.802(0.672-0.958)$ & 2.43 & $<0.015$ \\
\hline
\end{tabular}

The patients were further divided as per the $\mathrm{Ct}$ value which is an indirect measure of viral load. More than half of cases $(53.9 \%)$ were having low $\mathrm{Ct}$ value denoting a high viral load; moderate $C t$ value (20-28) had the minimum number $(15.4 \%)$ of cases. Blood groups A, B showed a higher proportion of cases in low $\mathrm{Ct}$ group; blood group A showing the highest percentage (1553, 65.3\%). On the other hand, $\mathrm{O}$ and $\mathrm{AB}$ blood groups had higher percentage of samples from high $\mathrm{Ct}$ (Fig. 2).

\section{Discussion}

The COVID-19 pandemic has till now grasped $190,597,409$ confirmed cases all over the world including 4093,145 deaths and numbers are rising daily [10]. Knowing the important risk factors come in handy to identify the at risk population, to add new precautions and judicious allocation of the available resources to prevent the wide spread infection and mortality. There is a dearth of knowledge on demographic and clinical risk element that controls the susceptibility to SARS CoV-2 infection and 
Table 3 Distribution of cases as per their admission status

\begin{tabular}{lllllr}
\hline Blood group & $\begin{array}{l}\text { Number of patient in Wards } \\
\text { (\% of total) }\end{array}$ & $\begin{array}{l}\text { Number of patients in } \\
\text { ICU(\% total) }\end{array}$ & $x^{2}$ value & $p$ value & $\begin{array}{l}\text { Odds ratio } \\
\text { (95\% Cl) }\end{array}$ \\
\hline A & $806(33.9)$ & $1573(66.1)$ & 9.112 & $<0.0001$ & $1.699(1.515-1.905)$ \\
B & $600(46.9)$ & $678(53.1)$ & 5.426 & $<0.0001$ & $0.702(0.617-0.798)$ \\
O & $551(46.9)$ & $623(53.1)$ & 5.117 & $<0.0001$ & $0.709(0.622-0.809)$ \\
AB & $69(40.8)$ & $100(59.2)$ & 0.083 & & 0.934 \\
Total & $2026(40.5)$ & $2974(59.5)$ & & & \\
\hline
\end{tabular}

Distribution of cases as per Ct values in qRT-PCR

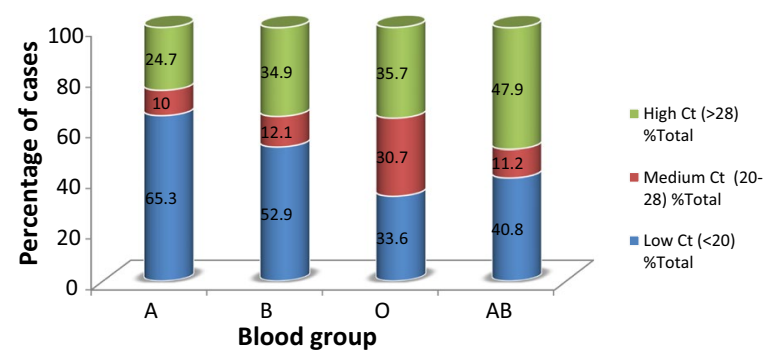

Fig. 2 Distribution of cases as per their $\mathrm{Ct}$ values in qRT-PCR for SARS-COV2

mortality. The risk factors identified till date include age, sex, few chronic conditions and laboratory findings. [11].

$\mathrm{ABO}$ gene is highly pleomorphic and differs widely across geographies and ancestry. This contains $\mathrm{A}$ and $B$ antigens on red cell surface encoded by two dominant and two recessive alleles located on chromosome 9q34.1-34.2 [12]. These antigens are also expressed on epithelial cells, platelets, vascular endothelial cells and neurons [13]. $\mathrm{ABO}$ antibodies are part of the innate immune system against parasites, bacteria and enveloped viruses, and these also act as receptors for many immune and inflammatory responses. [4, 14].

In our study, mean age of cases was higher than the controls (54.24 vs. 34. 67). Most of our cases belonged to age group 51-60. In other similar studies [3, 15, 16], age has been defined as a risk factor as well most common age group being the fifties. This is probably due to the fact that this is the age group of common predominance of several chronic illnesses as well as the natural immunological detritions associated with aging. In the present study, males outnumbered females like in previous similar studies. [3]

In this study, all of the blood groups except $\mathrm{AB}(\mathrm{A}, \mathrm{B}$, and $O$ ) showed a significant difference between cases and controls. Blood group A is associated with increased risk of infection (Odds ratio-2.552; CI 2.381-2.734; $p<0.0001)$. Blood group A constituted the highest percentage of cases while in controls blood group $\mathrm{O}$ was the commonest, which may suggest a protective effect of $\mathrm{O}$ phenotype. Many similar studies also found highest prevalence of A blood group in COVID 19 disease [5, $12,17,18]$. This finding is again consistent with coronavirus 2003 SARS outbreak data [19]. coronavirus receptor binds to ACE2 receptor [20] and anti-A antibody inhibits the interaction between SARS-CoV-2 and the ACE2 receptor [21]. This is the proposed mechanism by which $\mathrm{ABO}$ blood groups influence SARS-CoV-2 infection and COVID-19 disease severity $[5,12,18]$. A study has also found that people with blood group $\mathrm{O}$ are able to recognize certain proteins like the viral surface antigens as foreign and so less likely to get a disease [22]. Studies by Padhi et al. [9], Latz et al. [23], Almadhi et al. [24] and Liu et al. [25] across continents report blood type B as having higher risk of testing positive for SARS-CoV-2 infection contradicting our finding. Further known prothrombotic effect of non-O blood group may also be playing a role [26]. Different in results in these studies indicate other unexplored factors.

Assessment of severity in these patients was done in the present study by using their rate of admission to ICU for critical care support as well as $\mathrm{Ct}$ values as an indirect marker of the viral load. High viral load as denoted by low $\mathrm{Ct}$ value is one of the poor prognostic factors. In the present study, $65.3 \%$ of the blood group A patients were having high load of viruses in the body. Similarly, the rate of admission in ICU was significantly higher $p<0.001)$ in $\mathrm{A}, \mathrm{B}, \mathrm{O}$ blood groups. Blood group A cases had a significant risk of ICU admission (Odds ratio-1.699) while all other blood groups had a negative risk. In a similar study by Latz et al. [23] A blood group had highest risk of intubation and death. Another study proposed that individuals with B blood group had higher risk of intubation, but this group was associated with lower mortality than blood group $\mathrm{O}$ [18]. On the other hand, blood group $\mathrm{O}$ was found to be associated with lower mortality in a study [23]. The association of $\mathrm{ABO}$ blood group and COVID-19 severity may involve other factors like specific anti-A titers [27], the immunoglobulin isotype of anti-A antibodies [28], and ABO 
group differences in von Willebrand factor which need further clarification. [29].

\section{Conclusions}

Blood group A patients are more susceptible to COVID-19 in our subset. This blood group also has a significantly higher chance of critical care need as well as higher viral load. However, more studies with larger sampling particularly in community setting with an eye to nullify the effect of co-morbid conditions are necessary to confirm these findings. The mechanism of interaction between the $\mathrm{ABO}$ blood groups and ACE2 that forms the basis of this finding needs to be further investigated.

\section{Abbreviations}

ACE: Angiotensin converting enzyme; COVID-19: Coronavirus Disease -2019; $\mathrm{Cl}$ : Confidence interval; Ct: Cycle threshold; ICU: Intensive care unit; OR: Odds ratio; $p$ Value: Probability value; qRT-PCR: Quantitative real-time polymerase chain reaction; RNA: Ribonucleic acid; SARS: Severe acute respiratory syndrome; SARS- COV2: Severe acute respiratory syndrome coronavirus 2.

\section{Acknowledgements}

We acknowledge SOA University, Bhubaneswar, Odisha, for allowing us to do this work.

\section{Authors' contributions}

BB-Concepts, design, Data acquisition, manuscript preparation, manuscript editing, and manuscript review. BPR-Concepts, design, Data acquisition, manuscript preparation, manuscript editing, and manuscript review. RP—Data acquisition, manuscript editing, and manuscript review. SKK-Literature search, manuscript editing, and manuscript review. DS-Design, Data acquisition, manuscript editing, and manuscript review. KkS - Literature search, manuscript editing, and manuscript review. SO_Design, Definition of intellectual contents, literature search, manuscript preparation, manuscript editing, and manuscript review. Both BB and BPR have similar contribution to the work. All the authors have read and approved the manuscript.

\section{Funding}

No funds, grants or supports received for the work.

\section{Availability of data and materials}

Available with corresponding author.

\section{Declarations}

\section{Ethics approval and consent to participate}

The study was approved by institutional ethical committee (IEC) of IMS and SUM Hospital, SOA University, Bhubaneswar, Odisha via Ref.no/DRI/IMS.SH/ SOA/2021/174 dated 31st August 2021. This IEC is registered by registration number-ECR/627/Inst/OR/2014/RR-20. The samples collected for testing purpose was collected by a proper consent of all the patients who presented to the hospital for diagnosis and treatment. The study retrospectively analyzed them deriving from hospital records, and in the course of the study at no time, the patient records have been disclosed.

\section{Consent for publication}

All the coauthors agree for the publication in the present form.

\section{Competing interests}

The authors declare that they have no competing interest.
Received: 12 August 2021 Accepted: 7 November 2021

Published online: 20 January 2022

\section{References}

1. Arac E, Solmaz IH, Akkoc H et al (2020) Association between the Rh blood group and the covid-19 susceptibility. UHOD Int J Hematol Oncol 30:81-86

2. Fasina FO (2020) Novel coronavirus (2019-nCoV) update: What we know and what is unknown. Asian Pacific J Trop Med 13:97

3. Adhiah AH, Allami RH, Mohsin RH et al (2020) Evaluating of the association between ABO blood groups and coronavirus disease 2019 (COVID19) in Iraqi patients. Egyptian J Med Hum Genet 21:50

4. Cooling $L$ (2015) Blood groups in infection and host susceptibility. Clin Microbiol Rev 28:801-870

5. Li J, Wang X, Chen J et al (2020) Association between ABO blood groups and risk of SARS-CoV-2 pneumonia. Br J Haematol 190(1):24-27

6. Al khikani FHO (2020) The role of blood group in COVID-19 Infection: More information is needed. J Natl Sc Med 3(3):225-226

7. Arac E, Solmaz I, Akkoc H et al (2020) Association of Rh blood and COVID19 susceptibility. Int J Haemat Oncol 30:81-86

8. Goker H, Karakulak EA, Demiroglu H et al (2020) The effects of blood group types on the risk of COVID-19 infection and its clinical outcome. Turk J Med Sci 50(4):679-683

9. Padhi S, Suvankar S, Dash D et al (2020) ABO blood group system is associated with COVID-19 mortality: an epidemiological investigation in the Indian population. Transfus Clin Biol 27(4):253-258

10. WHO | World Health Organizationhttps://www.who.int

11. Zhou F, Yu T, Du R et al (2020) Clinical course and risk factors for mortality of adult in-patients with COVID-19 in Wuhan, China: a retrospective cohort study. Lancet 395(10229):1054-1062

12. Zhao J, Yang $Y$, Huang $\mathrm{H}$ et al (2021) Relationship between the $A B O$ blood group and the COVID-19 susceptibility. Clin Infect Dis 73(2):328-331

13. Storry JR, Olsson ML (2009) The ABO blood group system revisited: a review and update. Immunohematology 25:48-59

14. Jing W, Zhao S, Liu J et al (2020) ABO blood groups and hepatitis B virus infection: a systematic review and meta-analysis. BMJ Open 10:e034114

15. Mahmud R, Rassel MA, Monayem FB et al (2021) Association of ABO blood groups with presentation and outcomes of confirmed SARS CoV-2 infection: A prospective study in the largest COVID-19 dedicated hospital in Bangladesh. PLoS ONE 16(4):e0249252

16. Korean Society of Infectious Diseases, Korean Society of Pediatric Infectious Diseases, Korean Society of Epidemiology, Korean Society for Antimicrobial Therapy, Korean Society for Healthcare-associated Infection Control and Prevention, and Korea Centers for Disease Control and Prevention. Report on the epidemiological features of coronavirus disease 2019 (covid-19) outbreak in the republic of korea from January 19 to March 2, 2020. J Korean Med Sci. 2020; 35(10):e112.

17. Yu C, Zhou M, Liu Y et al (2020) Characteristics of asymptomatic COVID19 infection and progression: a multicenter, retrospective study. Virulence $11(1): 1006-1014$

18. Zietz M, Zucker J, Tatonetti NP (2020) Associations between blood type and COVID-19 infection, intubation, and death. Nat Commun 11:5761

19. Cheng Y, Cheng Y, Cheng G et al (2005) ABO blood group and susceptibility to severe acute respiratory syndrome. JAMA 293(12):1450-1451

20. Lu R, Zhao X, Li J et al (2020) Genomic characterisation and epidemiology of 2019 novel coronavirus: implications for virus origins and receptor binding. Lancet 395(10224):565-574

21. Guillon P, Clement M, Sebille V et al (2008) Inhibition of the interaction between the SARS-CoV spike protein and its cellular receptor by antihisto-blood group antibodies. Glycobiology 18(12):1085-1093

22. Hari. Blood type and COVID-19 risk: O may help, A may hurt. N Engl J Med 2020; 11:325-9.

23. Latz CA, De Carlo C, Boitano L et al (2020) Blood type and outcomes in patients with COVID-19. Ann Hematol 99:2113-2118

24. Almadhi MA, Abdulrahman A, Alawadhi A et al (2021) The effect of $A B O$ blood group and antibody class on the risk of COVID-19 infection and severity of clinical outcomes. Sci Rep 11:5745

25. Liu N, Zhang T, Ma L et al (2021) Te impact of ABO blood group on COVID-19 infection risk and mortality: A systemic review and 
meta-analysis. Blood Rev systematic review and meta-analysis. Blood Rev 48:100785

26. Anderson JL, May HT, Knight S et al (2021) Association of Sociodemographic Factors and Blood Group Type with Risk of COVID-19 in a US Population. JAMA Netw Open 4(4):e217429

27. Focosi D (2020) Anti-A isohemagglutinin titers and SARS-CoV2 neutralization: implications for children and convalescent plasma selection. Br J Haematol 190(30):e148-e150

28. Gerard C, Maggipinto G, Minon JM (2020) COVID-19 and ABO blood group: another viewpoint. Br J Haematol 190(2):e93-e94

29. Franchini M, Capra F, Targher G et al (2007) Relationship between ABO blood group and von Willebrand factor levels: from biology to clinical implications. Thromb J 5:14

\section{Publisher's Note}

Springer Nature remains neutral with regard to jurisdictional claims in published maps and institutional affiliations.

\section{Submit your manuscript to a SpringerOpen ${ }^{\odot}$ journal and benefit from:}

- Convenient online submission

- Rigorous peer review

- Open access: articles freely available online

- High visibility within the field

- Retaining the copyright to your article

Submit your next manuscript at $\boldsymbol{\nabla}$ springeropen.com 